\title{
Der Tod des Papstes Johannes Paul II. - ein wissenschaftlicher Vergleich von journalistischen Reaktionen auf den Tod des Papstes in Deutschland und in Polen
}

\section{The death of Pope John Paul II - A scientific comparison of journalistic reactions to the death of the Pope in Germany and in Poland}

\begin{abstract}
The aim of this article is to present the reactions of the Polish and German press to the death of Pope John Paul II, compare and analyze them. This approach allows to understand the differences between Polish and German perception of religion, particularly Christianity and the Catholic Church. Poland and Germany have different religious traditions, a different relationship to the church and to church dogma, rituals and piety. This may be observed as the different ways of looking at the death of Pope John Paul II in Polish and German newspapers.

Probably these perceptual differences ensued from the paternal figure of the John Paul II and special emotional Polish attitude to the deceased Polish Pope.
\end{abstract}

Keywords

Pope John Paul II, Catholic Church, press, Germany, Poland. 


\section{Vorgehensweise}

In diesem Artikel möchte ich die Reaktionen der polnischen und deutschen Presse, die auf den Tod von Papst Johannes Paul II. folgten, analysieren und vergleichen. Dieser Vergleich ermöglicht ein besseres Verständnis der Unterschiede zwischen polnischen und deutschen Religionsbetrachtungsweisen, insbesondere des Christentums und der katholischen Kirche. Polen und Deutschland haben verschiedene religiöse Traditionen, ein anderes Verhältnis zur Kirche sowie zu kirchlichen Dogmen, Ritualen und zur Frömmigkeit. Dies kann man besonders gut bei den unterschiedlichen Betrachtungsweisen vom Tod des Papstes Johannes Pauls II. in polnischen und deutschen Zeitungen beobachten. Im Hintergrund der Wahrnehmungsunterschiede kann höchstwahrscheinlich die polnische Herkunft des Papstes stehen, weil die Polen ein besonderes emotionales Verhältnis zum verstorbenen Papst haben.

In meiner Studie möchte ich die Zeitungen vergleichen, die dieselbe Ausrichtung repräsentieren. Am Anfang konzentriere ich mich auf Ähnlichkeiten und Unterschiede in den Berichten zum Tod des Papstes, die in den konservativen Zeitungen veröffentlicht wurden. Dazu gehören die „Frankfurter Allgemeine Zeitung“ in Deutschland, „Tygodnik Powszechny“ und „Przewodnik katolicki“ in Polen. Dann gehe ich zur liberalen Presse über und vergleiche die „Süddeutsche Zeitung“ mit den polnischen Zeitschriften: „Gazeta Wyborcza“ und „Rzeczpospolita“. Zum Schluss vergleiche ich kurz die Publikationen in den bunten Boulevardblättern, darunter „Bild“ in Deutschland, „Fakt“ und „Super-Express“ in Polen. In meiner Abhandlung konzentriere ich mich vor allem auf die allerersten Reaktionen der Zeitungen.

\section{Einleitung}

Am 12.2.2005 hat der deutsche Protestant Stephan Wackwitz in einem TAZ-Bericht geschrieben: „Vor zwei Jahren, im Sommer, fragte ich einen jungen Jesuiten, mit dem ich damals morgens joggte und abends manchmal Fahrrad fuhr, irgendwo zwischen Krakau und Wadowice auf einer jener endlosen, baumbeschatteten, praktisch autofreien Landstraßen, die sich durch Südpolen winden und auf denen man nach einer halben Stunde keine Sorgen mehr hat, außer der, in ein Schlagloch zu fahren, was in der Kirche wohl passieren werde, wenn Johannes Paul II. einmal nicht mehr sei. Er sah mich im Fahren kurz an. 
Dann grinste er, wie nur junge Jesuiten grinsen können und sagte: „Der stirbt nie." Ich glaube, das stimmt"1.

Leider war dieser Wunsch nicht zu erfüllen. Johannes Paul II. ist am Samstag, den 2. April 2005, im Alter von 84 Jahren, nach langem Todeskampf gestorben. Johannes Paul II. war zweifellos eine herausragende Persönlichkeit unserer Zeit, nicht nur wegen der Länge seines Pontifikats (fast 27 Jahre). Nach viereinhalb Jahrhunderten war er der erste, nicht italienische Heilige Vater in der langen, zweitausendjährigen Reihe von Päpsten der katholischen Weltkirche. Die Millionen haben ihn geliebt und verehrt. Manche Leute nannten ihn sogar respektvoll „Jahrhundert-Papst“, weil er nicht nur die Kirche, sondern auch die gesamte Menschheit in das dritte Millennium nach Christus geführt hat. Johannes Paul II. war der erste römische Pontifex, der - in einer Epoche der Massenmedien - aller Welt, auch Andersgläubigen und Ungläubigen, persönlich die Hand reichte.

Ab Samstagsabend, den 2. April, gab es für die Medien nur ein Thema: der Papst - sein Tod, sein Leben, sein Pontifikat. Nach dem Gewitter in den elektronischen Medien am Wochenende haben sich am Montag die „traditionellen“ Zeitungen aller Welt, auch in den nicht-katholischen Ländern, vor allem mit dem Tod des Papstes intensiv befasst.

\section{Ein kurzer Lebenslauf von Karol Wojtyła / Johannes Paul II.}

Am Anfang möchte ich kurz die große Persönlichkeit näher bringen ${ }^{2}$. Dem Papst Johannes Paul II. war eigentlich keine «klerikale» Karriere vorgezeichnet gewesen. Sein Lebenslauf bleibt ohne den Bezug auf seine polnischen Wurzeln unverstehbar. Karol Wojtyła wurde am 18. Mai 1920 in der südpolnischen Kleinstadt Wadowice geboren. Schon als Schüler und Student fand er seine Zuflucht in fast mönchischer Frömmigkeit. In der Nähe von Krakau, wo der strebsame junge Mann zunächst nicht Theologie, sondern Literatur und Philosophie zu studieren begann, rauchten bald die Krematorien im Konzentrationslager Auschwitz. In der Kriegs- und Besatzungszeit, als ein Zwanzigjähriger, entging er dank seiner fünfährigen, harten Arbeit für die chemischen Solvay-Werke (zuerst im Steinbruch, dann als Kesselreiniger), der Verschleppung zur

1 S. Wackowitz, Dieser Papst stirbt nie, „Tageszeitung” 7589/ (2005), S. 16.

${ }^{2}$ Vgl. „Pielgrzym nadziei“, Riders’s Digest Verlag, Warszawa 2001, S. 17- 328. 
Zwangsarbeit nach Deutschland. Gleichzeitig spielte er in einem Untergrund-theater in den Aufführungen von verbotenen polnischen Klassikern mit und tauchte schließlich unter im erzbischöflichen Palast Krakaus, wo er in einem geheimen Seminar Theologie gelehrt hat. Es war eine seltsame Mischung von Einflüssen, die sein ganzes Leben und seine Denkweise beeinflusst haben: Idealismus mit Realismus und Prinzipientreue, mehr romantisch als dogmatisch verstanden.

Im Alter von 58 Jahren, am 16. Oktober 1978 wurde Karol Wojtyła im achten Wahlgang zum Papst gewählt. Er war der jüngste Papst - seit 1846 und der erste Nichtitaliener auf dem Heiligen Stuhl - seit 1523. Schon beim Inaugurationsgottesdienst präsentierte er einen neuen Stil: Er ging auf die Versammelten zu, um die Kranken und die Kinder zu segnen. Bereits bei der ersten Wallfahrt, als katholischer Ober-Prokurator der Kirche, erklärte er die neue, auch politische Rolle der Kirche. Er sagte: „Die Kirche des Schweigens gibt es heute nicht mehr. Die Kirche spricht mit der Stimme des Papstes ${ }^{\text {“3 }}$. In seiner ersten Enzyklika Redemptor hominis (Christus- Erlőser der Menschen), vom März 1979, stellte er sein theologisches Programm dar. Diese Enzyklika gilt bis heute als eine Art Regierungserklärung. Der neue Papst ruft zur weltweiten Achtung der Menschenrechte sowie der Religions- und Gewissensfreiheit auf. Er warnt vor der Konsumgesellschaft und stellt die Menschen in den Mittelpunkt. Kennzeichnend für Johannes Paul II. war, dass er sowohl ein konservativer als auch ein revolutionärer Papst war. Anders als sein Vorgänger Paul VI. wurde er zum Medienstar, ein Global Player der Moral im Zeitalter der weltweiten Live-Übertragung. Anderseits aber kämpfte er gegen die „Theologie der Befreiung". Keiner von den führenden Menschen der Jahrtausendwende hat nach eigenen Maximen so konsequent gelebt, wie er. Er hatte den Mut, um Vergebung für die Sünden der Kirche zu bitten, darunter für die Glaubenskriege, die Inquisition und die Judenverfolgung. Die Einzigartigkeit des Papstes lag auch in seinem besonderen Kontakt zu den Massen. Die Modernität seiner Kommunikationsmittel, die Popularität unter ,jungen Menschen“, seine unverstellte Menschlichkeit gelten als unvergleichliche und sind "einsame Spitze“ in der Geschichte des römischen Papsttums. Die Rezipienten seiner Botschaft waren nicht in erster Linie die Kirche und ihre Gemeinden, sondern die Gesellschaft und ihre Medien.

\footnotetext{
${ }^{3}$ B. Bartoloni, Pole reißt Eisernen Vorhang ein, „Leipziger Volkszeitung“, 04.04.2005, S. 3.
} 
Man könnte sagen, dass dieser Pontifex der erste Medienpapst war. Er förderte eine ausgedehnte kirchliche Publizistik, sein Bild wurde auf Postkarten und Drucken hunderttausendfach verbreitet. Der Papst genoss ein außerordentliches Prestige. Seine Popularität kannte keine Grenzen. Manchmal gewinnt man den Eindruck, dass der Erfolg des Papstes auf seiner medienwirksamen Persönlichkeit basierte, die er für die Glaubenzwecke eingesetzt hat. Der Pontifex nutzte die Medien wie keiner der Vatikanregierenden zuvor aus und bekam auch am Ende seines Weges eine Medienaufmerksamkeit wie keiner auf dem Heiligen Stuhl.

„Ich bin froh, seid ihr es auch”. Das ist die letzte schriftliche Botschaft von dem Kirchenoberhaupt. Leider hat aber keine der weltlichen Zeitungen diesen Papstbefehl realisiert.

\section{Die Zeitungen}

4.1.

Fast die ganze Titelseite der „Frankfurter Allgemeine Zeitung“ (FAZ) wurde am 4. April dem verstorbenen Papst gewidmet. Auf der Titelseite der FAZ, die in der Regel ohne Illustrationen erscheint, erstreckte sich über die ganze Seitenbreite ein Schwarzweiß-Foto vom lächelnden Papst inmitten einer Menschenmenge. Nach der ersten Mondlandung, der deutschen Wiedervereinigung und den Anschlägen vom 11. September 2001 war dies erst das vierte Mal, dass die FAZ mit einem Foto auf der Titelseite erscheint ${ }^{4}$. In dem Artikel „Die Welt nimmt Abschied" unterstreicht die Zeitung die große Bedeutung des Heiliges Vaters nicht nur für die katholische Kirche, sondern auch für viele andere Menschen in der Welt. Die Zeitschrift führt weitläufig die Aussagen von Staats- und Regierungschefs nach dem Tod des Papstes an. Bundespräsident Köhler weist z.B. auf die „Entschlossenheit, die Konsequenz und das diplomatische Geschick“ des Papstes hin, der damit „die Freiheitsbewegung in Osteuropa inspiriert und begleitet“ hat, und der amerikanische Präsident Bush nennt den Papst „einen der größten moralischen Führer der Geschichte“.

Heinz-Joachim Fischer überlegt in seinem Artikel „Der die Menschen liebte“: „Nach welchen Maßstäben soll man diesen Papst und seine Amtszeit von mehr

${ }^{4}$ http://www.newsroom.at/news/display/print.cfm (07.04.2005), Zeitungen würdigen toten Papst auf Sonderseiten. 
als 26 Jahren beurteilen?"“. Er versucht, die Größe des Pontifex wiederzugeben. Der Papst gilt als Vorbild und moralische Autorität nicht nur für die katholischen Christen. Nach seinem Tod sei, laut Fischer, die Leere das vorherrschende Gefühl.

Auf der nächsten Seite befindet sich eine Chronik mit den wichtigen Ereignissen des Pontifikats und ein kurzer Text über die Auslandsreisen des Papstes. Der Autor berichtet, dass Johannes Paul II. der erste Papst war, der mehr als zweieinhalb Jahre seiner Amtszeit auf Reisen sowohl in Italien als auch im Ausland verbrachte ${ }^{5}$.

Auf der dritten Seite, neben dem Artikel über seine kirchliche Politik, gibt es auch ein Foto mit dem leidenden Papst, das über die Hälfte der Seite einnimmt. Daniel Deckers erklärt auf der vierten Seite das Verhältnis zwischen Johannes Paul II. und den Deutschen. Er erinnert an päpstliche Deutschlandbesuche, Gespräche des Papstes zwischen Repräsentanten der katholischen und evangelischen Kirche, die zur gemeinsamen Erklärung vom Vatikan und des Lutherischen Weltbundes über die Rechtfertigungslehre führten, und beschreibt das Verhältnis zu den deutschen Bischöfen ${ }^{6}$.

Anschließend folgen die Artikel, die schildern „wie Papst Johannes Paul II. und die Gewerkschaft Solidarność das Ende des Kommunismus herbeiführten“. Die Zeitung bringt auch den Inhalt der Ökumene-Enzyklika „Ut unum sint“"vom 25. Mai 1995 vor und beschreibt auf der nächsten Seite die Erfolge des Papstes im Bereich des Friedens, des interreligiösen Dialoges und der Verständigung zwischen den Kulturen ${ }^{7}$.

Für besonders interessant halte ich das Feuilleton von Dorota Masłowska, einer jungen polnischen Autorin, indem sie hochpathetisch, kraftvoll und zerknirscht ihre Gefühle und Erlebnisse am Sterbetag des Papstes beschreibt. „Nie im Leben habe ich mich so klein wie eine Laus gefühlt, und nie war mir es auch so klar gewesen, dass ich ein Mensch bin, nie habe ich mich so in die Welt verstrickt gefühlt. Ich bin zweiundzwanzig Jahre alt und sehe zum ersten Mal, was Geschichte ist, wie die Geschichte entsteht ${ }^{\text {" }}$ schreibt Masłowska.

${ }^{5}$ H-J. Fischer, Der Welt-Missionar, „Frankfurter Allgemeine Zeitung” 77 (2005), S. 2.

${ }^{6}$ D. Deckert, $Z u$ Gott, zu Gott wird es dich tragen, „Frankfurter Allgemeine Zeitung” 77 (2005), S. 4.

7 Staatstrauer In Lateinamerik; Respekt derMuslime; Bush: Ein Verfechter der Freiheit, „Frankfurter Allgemeine Zeitung” 77 (2005), S. 6.

${ }^{8}$ D. Maslowska, Ich weiß erst jetzt, was Geschichte ist, „Frankfurter Allgemeine Zeitung” 77 (2005). 
Ein weiterer Journalist, Konrad Schuller, berichtet über die traurige Atmosphäre in Tschenstochau, wo am 3. April im Kloster Jasna Góra die Landsleute von Karol Wojtyła Abschied genommen haben'.

Auf der Medienseite kommentiert Dirk Schümer die Haltung der italienischen Medien zum Tode des Papstes. Es fehlt auch nicht an Kritik über das Medienfieber und „kaum erträgliche, endlose, live Fernseh- und Radioübertragungen zum Tod Johannes Paul II. “10.

\section{2 .}

Die „FAZ“ möchte ich mit der katholischen Wochenzeitung „Tygodnik Powszechny“ vergleichen. Für Freitagabend, als der Papst im Sterben lag, hatte die Redaktion ursprünglich zu einer Jubiläumsfeier zum 60. Jahr ihres Bestehens mit kabarettistischem Rückblick eingeladen. Das Programm wurde stark verändert. Der Chefredakteur, Pfarrer Adam Boniecki, sagte, dass die Redaktion vor allem darüber nachdachte: „Wie wird die Kirche Polens, nach der Ausnahmesituation mit einem obersten Streitschlichter in Rom, den Weg zur Normalität zurückfinden? “. Alle Artikel, die die Zeitung in einer Sonderbeilage veröffentlichte, wirken weitaus nachdenklicher als die Texte in der FAZ. In den Artikeln sind sowohl die privaten Erlebnisse einzelner Autoren, Erinnerungen an die besonderen Verhältnisse zwischen dem Papst und der Redaktion von „Tygodnik Powszechny“, wo Karol Wojtyła als unbekannter Priester im 1949 einen Artikel veröffentlicht hat, als auch eine Beschreibung der polnischen Wurzeln des Papstes enthalten.

Chefredakteur Adam Boniecki gibt eine kurze Einleitung zur Sondersituation und nennt den Papst: „Johannes Paul den Großen“. „Er sprach mit allen. Er empfing die Menschen, die oft nicht heilig waren, Diktatoren und Anführer, die Blut an den Händen hatten: Pinochet, Arafat. Er wusste, dass ein Treffen und ein Gespräch mehr als verachtungsvolles Urteilen und absolute Abwendung bewirken konnte. Er sprach im Namen derer, von denen die Welt nicht viel wissen wollte. Von seiner Größe zeugen aber weder Worte noch Ereignisse. Diese sind das Ergebnis seiner Größe. Die Logik des Glaubens und sein grenzenloses

9 K. Schuller, Am Tor der Schmerzenmutter, „Frankfurter Allgemeine Zeitung” 77 (2005), S. 11.

${ }^{10}$ In medias res, „Frankfurter Allgemeine Zeitung” 77 (2005). 
Vertrauen in Gott haben ihm erlaubt, die Zeichen der Zeit richtig zu entziffern und zu beantworten" ${ }^{11}$.

Die Zeitung beschreibt auch die Stimmung von Angst um den Gesundheitszustand des Papstes, die am Freitag den 1. April in Polen herrschte. Dazu gehören die Berichte von Reaktionen der Gläubigen in verschiedenen polnischen Städten, die die Zeitung in dem Artikel „Der letzte Weg mit Ihm“"12 veröffentlichte. In der Publikation wurden viele Aussagen der Menschen zitiert: „Der Heilige Vater ist in Gottes Hand“, betonte eine Kirchgängerin in Krakau, der früheren Bischofsstadt von Karol Wojtyła. „Ich kann nur darauf hoffen, dass das Gebet etwas hilft" - sagte eine Warschauer Studentin mit Tränen in den Augen. „Ich bete jeden Tag für den Papst“, sagte die 73-jährige Czeslawa Tyrypon aus der Heimatstadt vom Papst - Wadowice. „Sein Leiden ist auch mein Leid“. Die Zeitung berichtet, dass viele Schulkinder am Freitag in Wadowice, in der Kirche in der der Papst vor 84 Jahren getauft wurde, die Erstkommunion empfing und später Messdiener war, für die Gesundheit des Papstes gebetet haben.

In einem anderen Artikel wird der Verlauf der Karwoche rekapituliert, und „die stille Ab- und Anwesenheit und das Leiden“ des Papstes unterstrichen. „Am Petersplatz schien alles so zu sein wie immer: eine weiße Gestalt mit der roten Stola um den Hals stand hoch oben im offenen Fenster. Aber die Kameras von 104 Fernsehsendern aus 84 Ländern zeigten uns von Nahem jede Geste, jede schmerzvolle Grimasse. Sie schufen eine besondere Nähe, die wir einerseits wollten, von der wir uns aber andererseits fürchten - um nicht Auge in Auge mit dem Leid zu stehen “13.

Dann informiert die Zeitung über die Staatstrauer um Johannes Paul II. Es werden die Erinnerungen der Jugendfreunde des Papstes, von bekannten Personen, in der Presse ausführlich veröffentlicht. Sie teilen ihre Eindrücke und Erlebnisse über die Bekanntschaft mit dem Papst mit ${ }^{14}$.

Bartek Dobroch und Michał Kuźmiński beschreiben in dem Artikel „Ich bin froh - seid ihr es auch!“ die größte Pilgerfahrt nach Rom in der Geschichte Polens. Nach Angaben der Autoren waren die Tickets für Sonderzüge und

11 A. Boniecki, Jan Paweł Wielki, „Tygodnik Powszechny” 15 (2005), S. 3.

12 B. Dobroch, M. Kuźmiński, Ostatnie z nim rekolekcje, „Tygodnik Powszechny” 15 (2005), S. 27.

${ }^{13}$ M. Zając, Nie gaśnie światłość, „Tygodnik Powszechny” 15 (2005), S. 6.

${ }^{14}$ K. Wiśniewska, Wiele wspomnień, „Tygodnik Powszechny” 15 (2005), S. 6-16. 
-busse schnell und restlos ausverkauft. Bis zu zwei Millionen Polen wollten Abschied von Johannes Paul II. nehmen. Es gab viele Studenten, die fast die ganze Nacht von Montag auf Dienstag für die Zugfahrkarten angestanden hatten. „Wir lieben den Papst, weil seinen Worten immer Taten folgten, deswegen empfinden wir auch den Weg nicht als besondere Anstrengung "15 sagen die Studenten. Auf dem Weg nach Rom haben sich auch viele Familien gemacht, die für den Fahrschein und das Reisegeld einen Kredit aufgenommen hatten. Sie möchten noch einmal den Papst treffen und seine Ausstrahlung erleben. Einen ähnlichen Ton schlagen auch die anderen katholischen Zeitungen in Polen in ihren Artikeln an (z.B. „Przewodnik Katolicki“). Die Artikel sind erinnerungsvoll und regen zum Nachdenken an. Sie enthalten auch viele Bezüge auf die polnische Geschichte und das päpstliche Verhältnis zum Heimatland. Sie behaupten, dass Johannes Paul II. hier nicht nur geliebt, sondern geradezu vergöttert wurde.

\section{3.}

Ich bin froh - seid ihr es auch!“ ruft der erste Titel in der „Süddeutschen Zeitung“ (SZ) aus. Im Vergleich zum ersten Artikel in der „Frankfurter Allgemeinen Zeitung“ beschreibt die SZ sowohl den Todeskampf des Papstes, seine letzten Stunden und die Weise, auf welche die Millionen Katholiken auf der ganzen Welt für das sterbende Kirchenoberhaupt gebetet hatten, als auch die Vorbereitungen für die Wahl seines Nachfolgers ${ }^{16}$.

Es werden die Reaktionen der Politiker aus aller Welt auf den Tod des Papstes dargestellt. Jeder unter den Mächtigen dieser Welt würdigt Johannes Paul II. als herausragende Persönlichkeit unserer Zeit. Auf der These basierend, dass „Johannes Paul II. ein Konservativer in Fragen des Glaubens und der Moral, aber ein Revolutionär im Verhältnis zur Vergangenheit der Kirche und zu anderen Religionen war", wird die Leserschaft zum nächsten Artikel von Matthias Drobinski übergeleitet. Er geht auf die Beschreibung des Pontifikats des verstorbenen Papstes ein ${ }^{17}$.

\footnotetext{
15 B. Dobroch, M. Kuźmiński, „Jestem radosny, wy też bądźcie”, „Tygodnik Powszechny”.

16 „Ich bin froh - seid ihr es auch“, „Süddeutsche Zeitung“ 76 (2005), S. 1.

17 M. Drobinski, Gottes beharrlicher Rebell, „Süddeutsche Zeitung“ 76 (2005), S. 2.
} 
Außerdem erörtert Matthias Drobinski auf der vierten Seite, dass „in nur wenigen Ländern Johannes Paul II. für eine so umstrittene Person wie in Deutschland gehalten war" ${ }^{\text {"18 }}$.

Auf den folgenden Seiten erfährt man alles über Karol Wojtyłas Lebenswerk und bekommt einen Bericht über Versammlungen von Trauernden in Deutschland, Polen und Rom.

Der polnische Journalist Adam Krzeminski stellt die anhaltende Bedeutung von Johannes Paul II. für die Kirche und vor allem für die Gesellschaft seines Landes heraus. Ihr „hinterlässt Karol Wojtyła ein gewaltiges Erbe, das allerdings von einigen grundsätzlichen Widersprüchen der polnischen Wirklichkeit unterminiert wird. Denn in der Kirche schwelt ein - von der Autorität des Papstes jahrelang kaum überdeckter - tiefgreifender Richtungskampf “19.

Der Soziologe Heinz Bude ehrt Johannes Paul II. als Vertreter des Unironischen in der ironischen Moderne. „Damit hat er sich im Laufe seiner Amtszeit zur Avantgardefigur der postsäkularen Gesellschaft gemacht, in der die Fragen des Glaubens nicht länger auf die des Wissens, des Geschäfts, des Rechts oder des Vergnügens reduziert werden können ${ }^{\text {"20. }}$.

\section{4.}

Und was wurde in Polen berichtet? „Polen hatte seinen König, von dem es geträumt hat“, erklärt in der polnischen Tageszeitung „Gazeta Wyborcza“ der sonst eher republikanisch gesinnte Adam Michnik. „Wir lebten in der Epoche von Johannes Paul II. - denn so wird das letzte Vierteljahrhundert genannt werden - des Papstes, der die katholische Kirche, Polen und sogar die Welt veränderte - und schließlich jeden von uns. ... Er stellte hohe Ansprüche. Deshalb rief er oft Widerspruch hervor. Die Worte des Widerspruchs änderten aber nie den Respekt und die Bewunderung des Nachfolgers von Petrus in Rom. Er lernte persönlich die beiden schrecklichsten Dämonen des 20. Jahrhunderts kennen - den Totalitarismus der Nazis und der Kommunisten. Die Schatten von Auschwitz und Kolyma begleiteten seine Lehre unaufhörlich ... Heute sind wir traurig. Die größte Autorität der Polen wird niemals zurückkehren. Und doch danken wir dem Schicksal, dass in unserem Leben dieser ungewöhnliche

${ }_{18}$ M. Drobinski, Die Trauer der Widerspenstigen, „Süddeutsche Zeitung“ 76 (2005), S. 4.

19 A. Krzemiński, Unser großer weißer Pater, „Süddeutsche Zeitung“ 76 (2005).

${ }^{20}$ H. Bude, Das Privileg der letzten Weihe, „Süddeutsche Zeitung“ 76 (2005). 
Stellvertreter Christi erschien, der so viel Gutes tat ${ }^{\text {“21. }}$. Viel Beachtung schenkt die Zeitung den Gerüchten, dass das Herz des verstorbenen Papstes möglicherweise in Polen bestattet wird. Es wäre eines „der schönsten Geschenke und Schätze “22, schreibt die Zeitung.

Auch die Trauerrede des Staatschefs Aleksander Kwasniewski, in der der Präsident sagt, dass Karol Wojtyła für sein Land in aller Welt mehr getan hatte als irgendjemand vor ihm, wird abgedruckt. Mit dem Tod des Papstes geht viel „für die polnische Position, für die polnische Politik" verloren. Die Zeitung erinnert sich an den ersten Besuch des Papstes in Polen 1979, als er rief: „Der Heilige Geist möge das Antlitz der Erde erneuern, dieser Erde ${ }^{\text {“23 }}$. Der Ruf fand sein Echo knapp ein Jahr später, als die Gewerkschaft „Solidarność“ entstand, und trug zum unaufhörlichen Zerfallsprozess des sogenannten realen Sozialismus nicht nur in Polen bei. Die polnischen Politiker betonen in „Gazeta Wyborcza“, dass sie aus Gesprächen mit ihm neue Energien zum Handeln schöpften. „Lech Walesa nennt diese Begegnungen ein Aufladen der Batterien “24 - schreibt die Zeitung.

Die Zeitung „Rzeczpospolita“ fügt dem eine bittere Beurteilung der polnischen Geschichte hinzu. „Johannes Paul II. war mit uns, als wir zu Solidarität und Freiheit erwachten, er war mit uns, als wir Freiheit und staatliche Unabhängigkeit dauerhaft erreichten. Was macht ihr mit eurer Freiheit? fragte er uns später im Ton eines Vaters, der beunruhigt über die Zukunft seiner Kinder ist. ... Johannes Paul II. stellte uns vor hohe Anforderungen, weil er zutiefst an den Menschen glaubte. Am letzten Tag seines Pontifikates konnte er nicht mehr sprechen und dennoch rief er zu Mut und Vertrauen auf, indem er mit Ruhe die Perspektive des Todes annahm und „heiter erlosch“. Das war seine letzte Predigt an uns. Leb wohl, Vater! “25.

Einen weiteren, interessanten Gesichtspunkt beschreibt die Publizistin Halina Bortnowska in "Gazeta Wyborcza“ - ihre Begegnungen mit dem Papst und die langen Gespräche mit ihm, als er noch Dozent an der katholischen Universität in Lublin war. „Er war oft fröhlich. Oder besser gesagt: frohgemut, kein ,lalala;

21 A. Michnik, Polska dostała króla, o jakim śniła, „Gazeta Wyborcza”, 03.04.2005, S. 2.

${ }^{22}$ W. Pelowski, Serce Jana Pawła II wróci do Ojczyzny?, „Gazeta Wyborcza”, 03.04.2005, S. 3.

${ }^{23}$ Narodowa Msza za Jana Pawła II., „Gazeta Wyborcza”, 05.04. 2005, S. 3.

${ }^{24}$ Pamiętam jak słuchał ludzi-wspomnienia o papieżu, „Gazeta Wyborcza”, 01.04.2005, S. $2-4$.

25 Zapisać smutek, „Rzeczpospolita” 79 (2005), S. 1. 
er wusste, Gott hat eine gute Welt erschaffen, sie war kein Fehler". Bortnowska, die am Aufbau von Hospizen in Polen beteiligt war, sorgt sich in dem Artikel um die richtige Einstellung jener Menschen, die den (damals noch lebenden) Papst in den letzten Tagen begleitet haben: „Man sollte einen Menschen gehen lassen. Nicht aufhalten, nicht belasten. Dasein und den Sterbenden in gute Gefühle hüllen, vor allem in Dankbarkeit. Ich bin mir nicht sicher, ob die Umgebung des Papstes das kann ${ }^{\text {“26. }}$.

Es wurden auch unzählige, ganzseitige Traueranzeigen für Johannes Paul II. publiziert, darunter vom polnischen Staatspräsidenten, von den Premierministern, von verschiedenen Verbänden bis hin zu einzelnen Firmen und Privatpersonen.

\section{5.}

Nun möchte ich zu dem Boulevardblatt „Bild“ kommen. Ich will mit der Kritik beginnen: „Ein herausragendes Beispiel mangelnder Pietät lieferte die „Bild“- Zeitung am 5. April. Wer kriegt das Herz vom toten Papst?, fragte sie auf der Titelseite. Das ist nicht nur geschmacklos in der Aussage, sondern auch noch grammatisch unsauber“ bemerkte der Spiegel ${ }^{27}$. „Bild“ schreibt weiter: „Polen wollen einen Teil ihres geliebten Johannes Paul II. haben“"28. Mit ihren Kommentaren möchte die Zeitung bestimmt ein großes Aufsehen erregen.

Im Artikel „Ist der Papst im Himmel oder im Fegefeuer?" versucht Weihbischof Dr. Hans-Jochen Jaschke auf die Frage zu antworten, ob es ein Leben nach dem Tod gibt. Am Ende seiner Ausführungen wünscht er Johannes Paul II. eine gute Ankunft bei Gott ${ }^{29}$.

Unter dem Artikel veröffentlicht die Zeitung die Erinnerungen von Halina Kwiatkowska, einer angeblichen Jugendfreundin von Karol Wojtyła. Sie beschreibt ihre Bekanntschaft mit Karol Wojtyła und ein Wiedersehen nach Jahren, bei dem sie mit Johannes Paul II. frühstückte ${ }^{30}$.

\footnotetext{
${ }^{26}$ H. Bortnowska, Uczył nas trudnej drogi, „Gazeta Wyborcza”, 02.04.2005, S. 4.

27 B. Sick, Der Papst ist tot, der Papst ist tot!, „Spiegel“, 06.04.2005.

${ }^{28}$ Wer kriegt das Herz vom toten Papst? „Bild“, 05.04.2005, S. 1.

${ }^{29}$ H-J. Jaschke, Ist der Papst im Himmel oder im Fegefeuer?, „Bild“, 05.04.2005, S. 4.

${ }^{30}$ Ich war die Jugendfreundin von Karol Wojtyla, „Bild“, 05.04.2005, S. 4.
} 
Auf der nächsten Seite berichtet Bild-Vatikan-Korrespondent Andreas Englisch von seinen Begegnungen mit dem Papst.

Am 6. April folgt eine Fortsetzung der Sensationshascherei. Aus dem Artikel "Geheime Papst-Wunder" kann man erfahren, dass der Papst ein blindes Mädchen, eine todkranke Frau und Gelähmte geheilt hat ${ }^{31}$. Auf der vierten Seite nennt die Zeitung den Papst eine Art „Pop Star" und vergleicht seine Beliebtheit mit der von Prinzessin Diana ${ }^{32}$.

4.6.

Die polnischen Boulevardzeitungen versuchten ihre Leser auf den Tod des Papstes schon am Samstag, den 2. April, vorzubereiten. Fast wie ein Abschied wirkt ein Papst-Zitat, das auf dem Titelblatt in der Boulevardzeitung „Fakt“ prangte: „Der Geist erlöscht nicht“. Gleichzeitig rief die Zeitung ihre Leser auf, für den Papst zu beten. „Gott, hilf ihm!“- hieß es im Leitartikel ${ }^{33}$.

„Er hat vor dem Tod keine Angst“", konstatiert die Zeitung „Super-Express“: „Wir sind es, die das Leben ohne ihn fürchten “"34.

In den nächsten Tagen berichtet „Super-Express“, dass unter den Tausenden, die sich in Gottesdiensten und in Freiluftmessen versammelten, um dem verstorbenen Papst zu gedenken, auch die Fußballfans von den beiden, seit Jahrhunderten miteinander verfeindeten, Warschauer Fußballmannschaften "Legia“ und „Polonia“ waren. Eine analoge Situation gab es in der Zeit auch in Krakau. Die Freunde der Vereine „Cracovia“ und „Wisła“ marschierten nebeneinander mit der Parole auf den Lippen: „Für dich, Heiliger Vater die Versöhnung”. „Die Löwen wohnen jetzt bei den Lämmern“ ${ }^{\text {“35 }}$ schreibt die Zeitung.

Die „Fakt“ berichtete noch, dass in Polen auch viele andere Versöhnungen gefeiert worden sind, die niemand mehr für möglich gehalten hat. Für die Polen scheint es unglaublich und seltsam zu sein, dass die zwei großen Persönlichkeiten, der Präsident Aleksander Kwasniewski und der erste polnischen Präsident

31 Geheime Papst-Wunder, „Bild“, 06.04.2005, S. 1.

${ }^{32}$ M. Gärtner, Warum wird der Papst im Tod plötzlich zum Pop-Star?, „Bild“, 06.04.2005, S. 4 .

${ }^{33}$ Boże pomóż Mu, „Fakt”, 02.04.2005, S. 1.

${ }^{34}$ Uczy nas wszystkich godnie umierać, „Super-Express”, 02.04.2005, S. 4.

35 Szaliki połaczone, „Super-Express”, 06.04.2005, S. 4. 
Lech Walesa, zusammen zur Begräbnisfeier angereist sind. Zur Überraschung aller haben die beiden Herren, die seit Jahren kein Wort miteinander gesprochen haben, nicht nur miteinander geredet, sondern sich auch, vor der versammelten Presse, die Hand gegeben und danach zusammen zu Mittag gegessen. „An dieses Wunder hätte nicht einmal Johannes Paul II. geglaubt“"36 kommentiert „Fakt“.

Sowohl „Fakt" als auch „Super Express" beschreiben die besondere Atmosphäre, die in Polen nach dem Tod von Johannes Paul II. herrschte. Nicht nur die überall anwesenden Trauerzeichen - überfüllte Kirchen, die betenden Menschen auf den Straßen, die brennenden Kerzen in den Fenstern - haben die Umwandlung verursacht. „Die Menschen haben sich geändert. Sie sind netter, leiser, höflicher zueinander. In der gemeinsamen, tiefen Trauer haben die Menschen den verlorenen Geist der Solidarität widergefunden“. Sehr interessant waren auch zwei Situationen, die in Polen beobachtet wurden - die schlesische Polizei meldete, dass unmittelbar nach den traurigen Ereignissen, die Kriminalität in der Region zwei Tage lang um ein Drittel zurückgegangen ist und dass die Mitarbeiter von Telekom Polska einen früher geplanten Streik abgesagt haben. Die Zeitungen nennen diese Gegebenheiten „das Wunder an der Weichsel" ${ }^{37}$.

\section{Fazit}

Als zusammenfassende Schlussbemerkung kann ich feststellen, dass sich die deutschen Zeitungen mehr auf die Analyse des Erfolges von Johannes Paul II. konzentrierten, während die polnischen Zeitungen eher die Gemütslage Polens übermittelten. Sowohl „Frankfurter Allgemeine Zeitung“ als auch „Süddeutsche Zeitung" ziehen eine kirchenpolitische Bilanz aus den 26 Amtsjahren Papst Johannes Pauls II. und versuchen den deutschen Lesern die Person sowie die Lehre des verstorbenen Papstes näher zu bringen. Genau und ausführlich beschreiben sie sein Leben, sein Pontifikat, seine Erfolge und deren Bedeutung für die Weltgeschichte. „Bild“ sucht dagegen in diesem Ereignis nach Sensation.

Die polnischen Zeitungen (besonders die katholischen) konzentrieren sich mehrheitlich auf die Erinnerungen an Karol Wojtyła und die Beschreibung der Erlebnisse einzelner Polen mit ihm. Viele Artikel übermitteln meistens

\footnotetext{
${ }^{36}$ Czy duch odnowił oblicze tej ziemi?, „Fakt”, 09.04.2005, S. 2.

${ }^{37}$ Pogodził ogień $z$ woda, „Super-Express”, 08.04.2005, S. 2.
} 
persönliche, ergreifende Eindrücke. Die liberalen Zeitungen würdigen die politische Rolle des Papstes in der polnischen Geschichte. Die Boulevardzeitungen beobachten vor allem die Verwandlung des gesamten Landes nach dem Tod von Johannes Paul II.

Indes ist anzumerken, dass sich hinter all den Titeln, Adjektiven und Superlativen ein vergeblicher Versuch verbirgt: Person und Wirken von Papst Johannes Paul II. zu beschreiben. Dies ist leider besonders aussichtslos deshalb, weil das Leben von Karol Wojtyła im wahrsten Sinne des Wortes unbeschreiblich ist.

\section{Bibliography}

Bartoloni B., Pole reißt Eisernen Vorhang ein, „Leipziger Volkszeitung“, 04.04.2005.

Boniecki A., Jan Pawet Wielki, „Tygodnik Powszechny” 15 (2005), S. 3-4.

Bortnowska H., Uczył nas trudnej drogi, „Gazeta Wyborcza”, 02.04.2005.

Boże pomóż Mu, „Fakt”, 02.04.2005.

Bude H., Das Privileg der letzten Weihe, „Süddeutsche Zeitung“ 76 (2005), S. 13.

Czy duch odnowił oblicze tej ziemi?, „Fakt”, 09.04.2005.

Deckert D., Zu Gott, zu Gott wird es dich tragen, „Frankfurter Allgemeine Zeitung” 77 (2005).

Dobroch B., Kuźmiński M., Ostatnie z nim rekolekcje, „Tygodnik Powszechny” 15 (2005), S. 27.

Dobroch B., Kuźmiński M., „Jestem radosny, wy też bądźcie”, „Tygodnik Powszechny” 16 (2005), S. 10.

Drobinski M., Gottes beharrlicher Rebell, „Süddeutsche Zeitung“ 76 (2005), S. 2.

Drobinski M., Die Trauer der Widerspenstigen, „Süddeutsche Zeitung“ 76 (2005), S. 4.

Fischer H-J., Der Welt-Missionar., „Frankfurter Allgemeine Zeitung” 77 (2005).

Gärtner M., Warum wird der Papst im Tod plötzlich zum Pop-Star?, „Bild“, 06.04.2005.

Geheime Papst-Wunder, „Bild“, 06.04.2005.

„Ich bin froh - seid ihr es auch“, „Süddeutsche Zeitung“, 76 (2005), S. 1.

Ich war die Jugendfreundin von Karol Wojtyla., „Bild“, 05.04.2005.

Jaschke H-J., Ist der Papst im Himmel oder im Fegefeuer?,,Bild“, 05.04.2005.

Krzemiński A., Unser großer weißer Pater, „Süddeutsche Zeitung“ 76 (2005), S. 13.

Maslowska D., Ich weiß erst jetzt, was Geschichte ist, „Frankfurter Allgemeine Zeitung” 77 (2005).

Michnik A., Polska dostała króla, o jakim śniła, „Gazeta Wyborcza”, 03.04.2005, S. 2.

Pamiętam jak stuchał ludzi- wspomnienia o papieżu, „Gazeta Wyborcza”, 01.04.2005. 
Pelowski W., Serce Jana Pawła II wróci do Ojczyzny? „Gazeta Wyborcza”, 03.04.2005, S. 3.

Pogodził ogień z woda, „Super-Express”, 08.04.2005.

Sick B., Der Papst ist tot, der Papst ist tot!, „Spiegel“, 06.04.2005.

Staatstrauer In Lateinamerika; Respekt der Muslime; Bush: Ein Verfechter der Freiheit. „Frankfurter Allgemeine Zeitung” 77 (2005).

Szaliki połaczone, „Super-Express”, 06.04.2005.

Schuller K., Am Tor der Schmerzensmutter, „Frankfurter Allgemeine Zeitung” 77 (2005), S. 11.

Uczy nas wszystkich godnie umierać, „Super-Express”, 02.04.2005.

Vgl, Pielgrzym nadziei, Riders's Digest Verlag, Warszawa 2001, S. 17-328.

Narodowa Msza za Jana Pawła II, „Gazeta Wyborcza”, 05.04.2005.

Wackowitz S., Dieser Papst stirbt nie, „Tageszeitung” 7589 (2005).

Wer kriegt das Herz vom toten Papst?, „Bild“, 05.04.2005.

Wiśniewska K., Wiele wspomnień, „Tygodnik Powszechny” 15 (2005), S. 6-16.

Zając M., Nie gaśnie światłość, „Tygodnik Powszechny” 15 (2005), S. 6. 